\title{
ANIMASI INTERAKTIF PENGENALAN DASAR BAHASA INGGRIS PADA TK AN-NURUDDIN DEPOK
}

\author{
Nur Azizah ${ }^{1}$ \\ Belsana Butar Butar ${ }^{2}$ \\ Indah Tri Wahyuni ${ }^{3}$ \\ Dosen Program Studi Sistem Informasi STMIK Raharja ${ }^{1}$, Dosen Program Studi Manajemen \\ Informatika AMIK BSI Jakarta², Dosen Program Studi Sistem Informasi STMIK Nusa Mandiri \\ Jakarta $^{3}$ \\ Email: nur.azizah@raharja.infol ${ }^{1)}$, belsana1@gmail.com ${ }^{2)}$, itriwahyuni54@gmail.com $^{3)}$
}

\begin{abstract}
ABSTRAK
Mengenalkan dasar Bahasa Inggris untuk peserta didik taman kanak-kanak (TK) sangatlah penting di saat ini, terutama dalam persiapan anak untuk memasuki pendidikan selanjutnya. Dengan mengenalkan dasar Bahasa Inggris terhadap peserta didik diharapkan anak-anak dapat menambah materi dan dapat mengingat dengan baik sehingga anak-anak dapat mengembangkan pola berpikir yang kreatif pada diri anak. Terdapat suatu hal yang perlu diperhatikan dalam menentukan metode pembelajaran untuk memotivasi peserta didik belajar dengan efektif serta menyenangkan diperlukan sumber belajar atau alat peraga yang menarik dan menyenangkan. Untuk pembelajaran interaktif dipilih media pembelajaran dengan menggunakan media animasi interaktif yang berisi gambar bergerak, suara serta tulisan dengan tujuan untuk meningkatkan motivasi peserta didik agar mutu dan kualitas belajarnya semakin maju dan membantu para guru untuk menciptakan alat bantu ajar untuk pengenalan dasar Bahasa Inggris kepada para peserta didik secara efektif, sehingga proses pembelajaran menjadi lebih menyenangkan dan dapat meningkatkan kualitas hasil belajarnya nantinya.
\end{abstract}

Kata kunci: Animasi Interaktif, Pengenalan Bahasa Inggris.

\begin{abstract}
Introduce basic of English for kindergarten (TK) is important for this time, especially preparation the child for entering further education. Introducing basic of English language to learners are expected that children can add material and can remember well so children can develop creative ways of thinking in children. There are some things to consider in determining learning methods for motivating learners to learn effectively and fun needed resources or props learning interesting and fun. or interactive learning learning media selected using interactive animated media moving image, sound and writing with a purpose to improve the motivation of learners so that the quality and the quality of their learning more advanced and helping teachers to create learning tools for a basic introduction to the language of the United Kingdom to learners as effectively, so the learning process becomes more enjoyable and can improve the quality of their learning results later.
\end{abstract}

Keywords: Interactive Animation, Introduction English Language. 


\section{PENDAHULUAN}

\section{A. Latar Belakang Masalah}

Saat ini pendidikan sangatlah berperan penting terhadap perkembangan anak, pendidikan yang dimulai sejak dini akan memberikan hasil yang lebih optimal ketimbang memulainya ketika sejak usia dewasa. Hal tersebut dikarenakan ingatan anak usia dini yang masih tajam sehingga mereka mudah mengingat apa yang mereka pelajari. Salah satu materi yang penting untuk anak usia dini berupa pengenalan dasar-dasar Bahasa Inggris. Pelajaran Bahasa Inggris paling dasar bagi peserta didik Di TK Islam An-Nuruddin mengenai pengenalan alphabet, number, transportation, regards dan colours. Para guru TK Islam An-Nuruddin masih menerapkan sistem pembelajaran dengan menerangkan materi pembelajaran di depan kelas dengan menggunakan papan tulis dan menggunakan media buku, hal tersebut dirasa kurang efektif bagi peserta didik dalam mengikuti dan menerima pembelajaran. Sehingga membuat para peserta didik kurang tertarik dan cepat merasa bosan pada saat belajar dasar-dasar Bahasa Inggris.

\section{B. Landasan Teori}

a. Animasi

"Animasi berasal dari bahasa latin yaitu "anima" yang berarti jiwa, hidup, nyawa dan semangat. Sedangkan animasi secara utuh diartikan sebagai gambar yang memuat objek seolah-olah hidup, disebabkan oleh kumpulan gambar itu berubah beraturan dan bergantian”. [3]

b. Multimedia

"Multimedia adalah kombinasi dari paling sedikit dua media input atau output dari data, dimana media tersebut dapat berupa audio (suara dan musik), animasi, video, teks, grafik dan gambar".[1]

c. Pembelajaran

"Pembelajaran adalah suatu kombinasi yang tersusun meliputi unsur-unsur manusiawi, material, fasiltas, perlengkapan dan prosedur yang saling mempengaruhi mencapai tujuan pembelajaran".[4]

d. Storyboard

"Storyboard secara sederhana dapat diartikan sebagai papan cerita. Dalam pengertian yang lebih luas, storyboard merupakan rangkaian gambar sketsa yang mempresentasikan alur sebuah cerita. Storyboard berfungsi sebagai alat perencanaan yang memadukan antara narasi dan visual"..[2]

e. Pengujian Whitebox Testing

"White box testing secara umum merupakan jenis testing yang lebih berkonsentrasi terhadap isi dari perangkat lunak itu sendiri. Jenis ini lebih banyak berkonsentrasi pada source code dari perangkat lunak yang dibuat sehingga membutuhkan proses testing yang jauh lebih lama dan lebih "mahal" dikarenakan dibutuhkan ketelitian dari para tester serta kemampuan teknis pemrograman bagi para testernya". [5]

\section{Identifikasi Masalah}

a. Sistem pembelajaran yang saat ini sedang diterapkan oleh para Guru kurang efektif untuk memacu peserta didik memahami materi dengan cepat..

b. Peserta didik kurang tertarik terhadap pengenalan dasar Bahasa Inggris melalui media pembelajaran secara konvensional.

\section{Tujuan Penelitian}

Tujuan dari penelitian ini adalah:

a. Untuk mengembangkan sistem pembelajaran berupa animasi interaktif.

b. Untuk memotivasi anak usia dini agar lebih tertarik dan senang untuk mempelajari dasar dari Bahasa Inggris.

c. Menciptakan media pembelajaran yang menyenangkan dan tidak membosankan bagi peserta didik.

\section{METODE PENELITIAN}

Pembuatan media pembelajaran berupa animasi interaktif menggunakan metode Model Air Terjun (Waterfall). Tahapan-tahapan yang digunakan dalam metode penelitian ini, sebagai berikut: 
a. Analisis

Mengumpulkan data dan informasi apa saja yang dibutuhkan oleh guru dan peserta didik dalam membangun media pembelajaran secara interaktif

b. Design (Desain)

Hasil dari analisa tersebut, merupakan dasar mendesain animasi pengenalan dasar Bahasa Inggris dengan menggunakan storyboard.

c. $\quad$ Pengkodean (Coding)

Tahap ini dilakukan pengkodean dari desain rancangan tampilan yang sudah dibuat dengan menggunakan bahasa pemrograman Action Script yang ada pada Software Adobe Flash Proffesional CS6.

d. Pengujian (Testing)

Melakukan pengujian terhadap program tersebut dengan menggunakan whitebox testing sehingga dapat dipastikan keluaran yang dihasilkan sesuai.

\section{HASIL DAN PEMBAHASAN}

\section{A. Analisa Kebutuhan}

Sejalan dengan tujuan penelitian, maka diperlukan informasi-informasi yang meliputi analisa kebutuhan salah satunya kebutuhan fungsionalnya.

1. Pada animasi interaktif ini dapat memunculkan 4(empat) menu utama yang dapat dipilih yaitu menu lesson, menu exercise, menu games, dan tombol exit. Didalam menu lesson terdapat materi pembelajaran, diantaranya: menu alphabet, menu number, menu human body, menu transportation, menu regards dan menu colours.

2. Pada animasi interaktif ini mampu menampilkan materi berupa teks, gambar, serta suara.

\section{B. Perancangan Animasi Interaktif}

a. Perancangan Storyboard

1. Storyboard Opening

Berikut ini adalah gambaran dari storyboard opening yang dijelaskan pada tabel di bawah ini:

Tabel 1. Storyboard Opening

\begin{tabular}{|c|c|c|}
\hline VISUAL & SKETSA & AUDIO \\
\hline $\begin{array}{l}\text { Ini merupakan } \\
\text { gambaran } \\
\text { tampilan dari } \\
\text { halaman } \\
\text { pembuka dari } \\
\text { pengenalan } \\
\text { dasar Bahasa } \\
\text { Inggris. } \\
\text { Dengan tulisan } \\
\text { Welcome } \\
\text { Lalu } \\
\text { selanjunnun } \\
\text { otomatis lanjut } \\
\text { ke halaman } \\
\text { judul. }\end{array}$ & Welcome ... & $\begin{array}{l}\text { Music: } \\
\text { ImHappy.wav }\end{array}$ \\
\hline
\end{tabular}

2. Storyboard Halaman Judul

Berikut ini adalah gambaran dari storyboard halaman utama yang dijelaskan pada tabel di bawah ini: 
Tabel 2. Storyboard Halaman Utama

\begin{tabular}{|c|c|c|}
\hline VISUAL & SKETSA & AUDIO \\
\hline $\begin{array}{l}\text { Ini merupakan } \\
\text { gambaran } \\
\text { tampilan dari } \\
\text { halaman judul } \\
\text { dari } \\
\text { pengenalan } \\
\text { dasar Bahasa } \\
\text { Inggris. } \\
\text { Dengan pesan } \\
\text { Selamat } \\
\text { Belajar. Lalu } \\
\text { ada tombol } \\
\text { button ok } \\
\text { untuk lanjut } \\
\text { pada halaman } \\
\text { berikutnya } \\
\text { yaitu menu } \\
\text { utama. }\end{array}$ & Lets Study English & $\begin{array}{l}\text { Music: } \\
\text { ImHappy.wav } \\
\text { Buttonmp3.wa } \\
\text { v }\end{array}$ \\
\hline
\end{tabular}

3. Storyboard Menu Utama

Berikut ini adalah gambaran dari storyboard menu utama yang dijelaskan pada tabel di bawah ini:

Tabel 3. Storyboard Menu Utama

\begin{tabular}{|l|l|l|}
\hline \multicolumn{1}{|c|}{ VISUAL } & \multicolumn{1}{|c|}{ SKETSA } & AUDIO \\
\hline $\begin{array}{l}\text { Menampillan } \\
\text { menu utama } \\
\text { yang berisi } \\
\text { button } \\
\text { alphabet, } \\
\text { button number, } \\
\text { button part of } \\
\text { body, button } \\
\text { close dan } \\
\text { button profil. }\end{array}$ & $\begin{array}{l}\text { Music: } \\
\text { Music2.wav } \\
\text { mousedown.wav }\end{array}$ & \\
\hline Lesson & & \\
\hline
\end{tabular}

4. Storyboard Menu Lesson

Berikut ini adalah gambaran dari storyboard menu lesson yang dijelaskan pada tabel di bawah ini:

Tabel 4. Storyboard Menu Lesson

\begin{tabular}{|c|c|c|}
\hline VISUAL & SKETSA & AUDIO \\
\hline $\begin{array}{l}\text { Menampilkan } \\
\text { menu lesson } \\
\text { atau menu } \\
\text { materi } \\
\text { pembelajaran } \\
\text { yang terdiri } \\
\text { dari menu } \\
\text { Alphabet, } \\
\text { Number, } \\
\text { Transportation } \\
\quad \text { Regards, } \\
\text { Human Body, } \\
\text { dan Colours. } \\
\text { Didalah } \\
\text { storyboard } \\
\text { tersebut } \\
\text { terdapat button } \\
\text { home untuk } \\
\text { kembali ke } \\
\text { menu utama }\end{array}$ & $\left(\begin{array}{c}\text { alpha } \\
\text { bets }\end{array}\right)$ & $\begin{array}{l}\text { Musicic: } \\
\text { Menu_lesson.wat } \\
\text { mouseDown.wav }\end{array}$ \\
\hline
\end{tabular}


5. Storyboard Menu Alphabet

Berikut ini adalah gambaran dari storyboard menu alphabet yang dijelaskan pada tabel di bawah ini:

Tabel 5. Storyboard Menu Alphabet

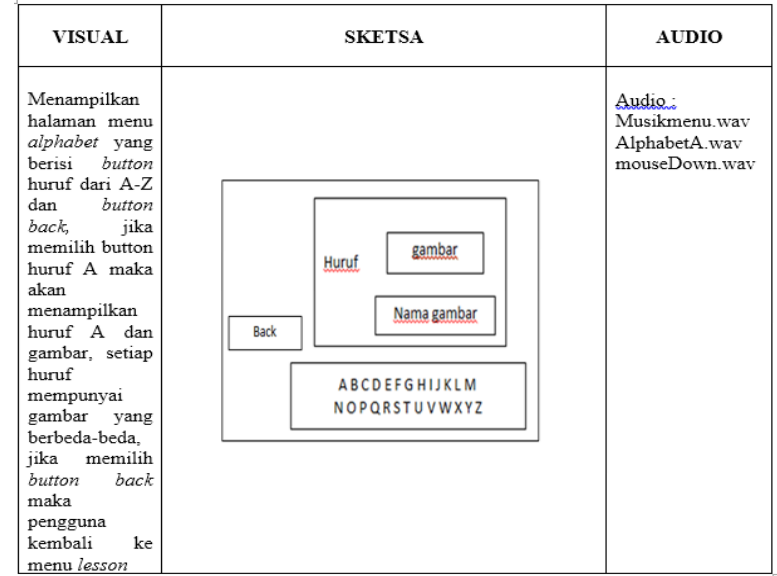

6. Storyboard Menu Number

Berikut ini adalah gambaran dari storyboard menu number yang dijelaskan pada tabel di bawah ini:

Tabel 6. Storyboard Menu Number

\begin{tabular}{|l|c|c|}
\hline \multicolumn{1}{|c|}{ VISUAL } & \multicolumn{1}{|c|}{ SKETSA } & \multicolumn{1}{c|}{ AUDIO } \\
\hline $\begin{array}{l}\text { Menampilkan } \\
\text { menu number } \\
\text { dari masing } \\
\text { masing tombol } \\
\text { button angka } \\
\text { yang tersedia, } \\
\text { dan } \\
\text { menampilkan } \\
\text { tampilan } \\
\text { dengan button } \\
\text { yang dipilih. }\end{array}$ & $\begin{array}{l}\text { Mussic. } \\
\text { ONE.wav } \\
\text { musikmenu.wav } \\
\text { mousedown.wav }\end{array}$ & \\
\hline
\end{tabular}

7. Storyboard Menu Transportation

Berikut ini adalah gambaran dari storyboard menu transportation yang dijelaskan pada tabel di bawah ini :

Tabel 7. Storyboard Menu Transportation

\begin{tabular}{|c|c|c|c|}
\hline VISUAL & \multicolumn{2}{|c|}{ SKETSA } & AUDIO \\
\hline $\begin{array}{l}\text { Menampilkan } \\
\text { beberapa } \\
\text { pilihan menu } \\
\text { alat } \\
\text { transportasi } \\
\text { dimulai dari } \\
\text { transportasi } \\
\text { darat, laut } \\
\text { maupun } \\
\text { transportasi } \\
\text { udara. }\end{array}$ & $\begin{array}{l}\text { Land Transportzion } \\
\text { Transportas Parar }\end{array}$ & $\begin{array}{l}\text { Air Transportzation } \\
\text { Itracseortad Vidaca }\end{array}$ & $\begin{array}{l}\text { Music: } \\
\text { Delicious2 } \\
\text { guitar.wav } \\
\text { mouseDown.wav }\end{array}$ \\
\hline
\end{tabular}


8. Storyboard Exercise

Berikut ini adalah gambaran dari storyboard exercise yang dijelaskan pada tabel di bawah ini:

Tabel 8. Storyboard Menu Exercise

\begin{tabular}{|l|c|l|}
\hline \multicolumn{1}{|c|}{ VISUAL } & SKETSA & AUDI0 \\
\hline $\begin{array}{l}\text { Dalam gambar } \\
\text { storyboard } \\
\text { tersebut } \\
\text { terdapat soal } \\
\text { pertanyaan dan } \\
\text { pilihan jawaban } \\
\text { dengan tombol } \\
\text { button. Button } \\
\text { panah untuk } \\
\text { kembai ke } \\
\text { menu utama. }\end{array}$ & Pertanyaan & $\begin{array}{l}\text { Mussic. } \\
\text { Button.wav } \\
\text { Four.wav }\end{array}$ \\
\hline
\end{tabular}

9. Storyboard Games

Berikut ini adalah gambaran dari storyboard exercise yang dijelaskan pada tabel di bawah ini:

Tabel 9. Storyboard Menu Games

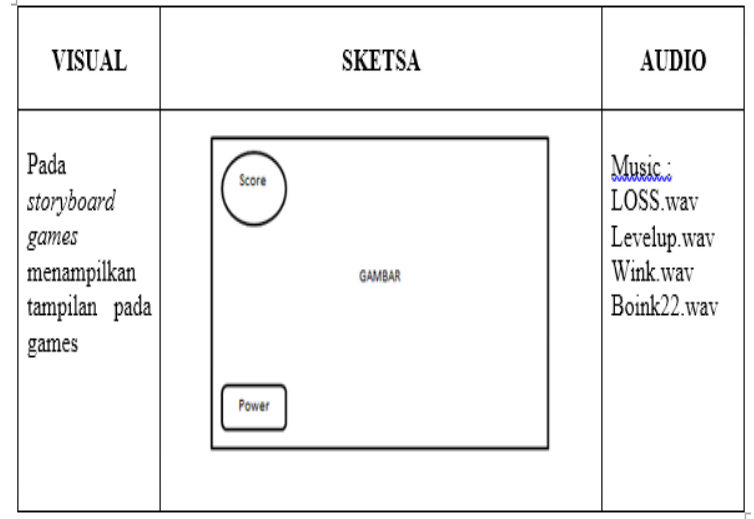

\section{a. Rancangan Antar Muka (User Interface)}

1. Halaman Opening

Halaman opening menampilkan teks Welcome, halaman ini akan otomatis masuk ke halaman judul.

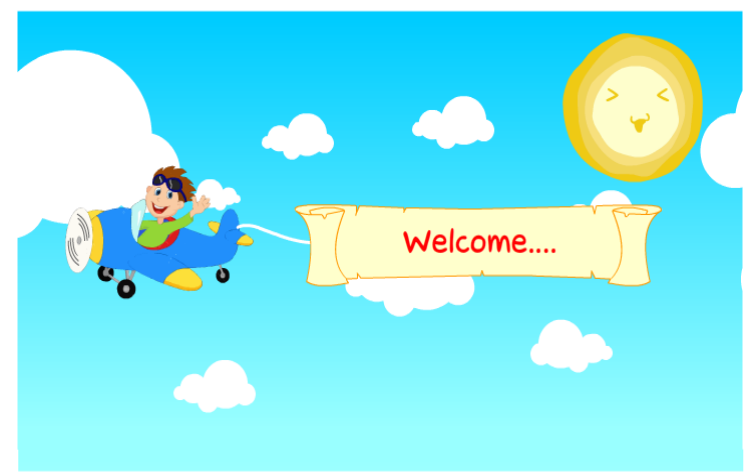

Gambar 1. User Interface halaman Opening 
2. Halaman Judul

Halaman ini menampilkan judul aplikasi yang sedang dimainkan, klik button Ok untuk melanjutkan dan memasuki ke halaman menu utama.

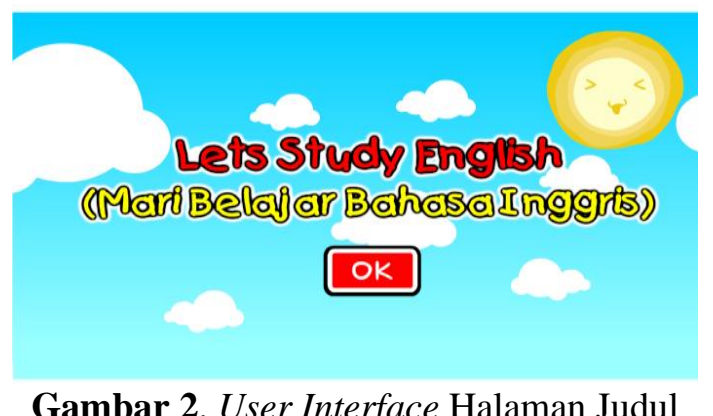

3. Halaman Menu Utama

Halaman menu utama ini berisi 4 tombol menu Lesson sebagai menu materi pembelajaran, menu exercise sebagai menu latihan soal-soal, menu games sebagai menu permainan yang mempunyai 3(tiga) level, dan tombol exit untuk keluar dari aplikasi sekaligus menampilkan profil sebagai identitas diri.

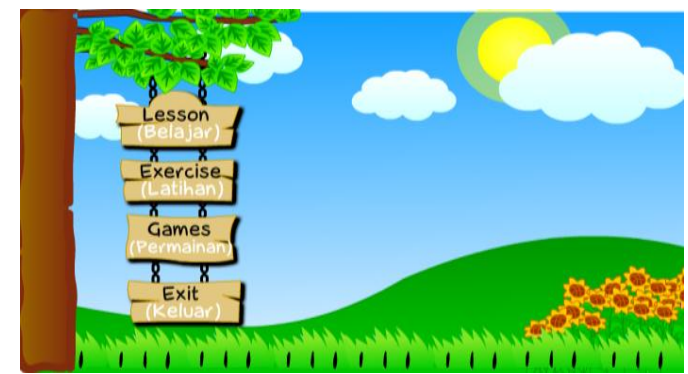

Gambar 3. User Interface Halaman Menu Utama

4. Halaman Menu Lesson

Halaman ini menampilkan sub-menu lesson yang terdapat pilihan berupa button, yaitu: alphabet, number, transportation, regards, human body dan colours. Pada sub-menu lesson terdapat juga button home untuk kembali ke menu utama.

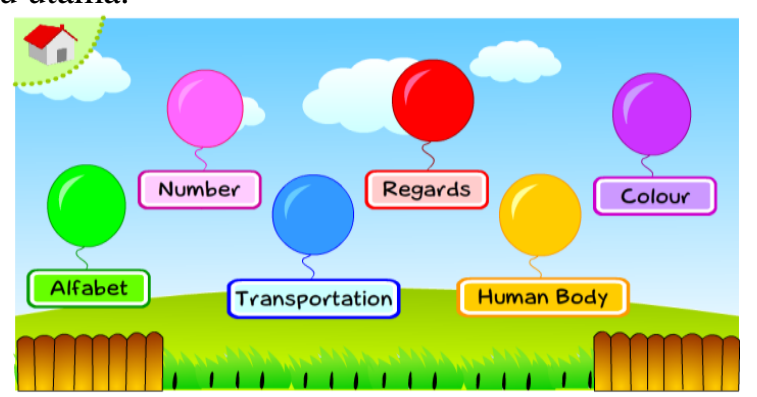

Gambar 4. User Interface Halaman Menu Lesson

5. Halaman Menu Alphabet

Halaman ini menampilkan button huruf dari A-Z, dan halaman ini menampilkan huruf dan gambar, terdapat juga button back untuk kembali ke menu sub-menu lesson. 


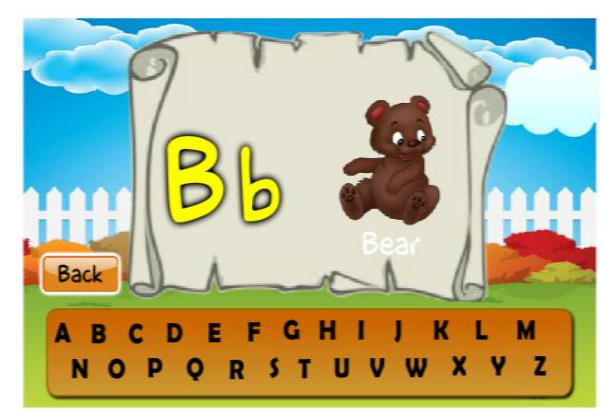

Gambar 5. User Interface Halaman Menu Alphabet

6. Halaman Number

Halaman Number ini berisi 12 button yang berupa button angka dari 0 sampai 10, dan terdapat juga button kembali untuk kembali ke sub-menu lesson.

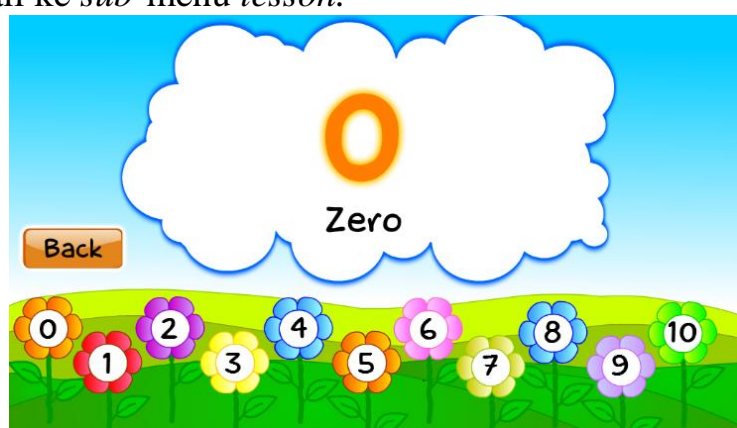

Gambar 6. User Interface Halaman Menu Number

\section{Halaman Menu Transportation}

Pada halaman menu transportation ini berisi 4 button yang berupa button transportasi darat untuk menampilkan macam-macam transportasi darat, transportasi air untuk menampilkan macam-macam transportasi air, transportasi udara untuk menapilkan macam-macam transportasi udara dan terdapat juga button back untuk kembali ke sub-menu lesson.

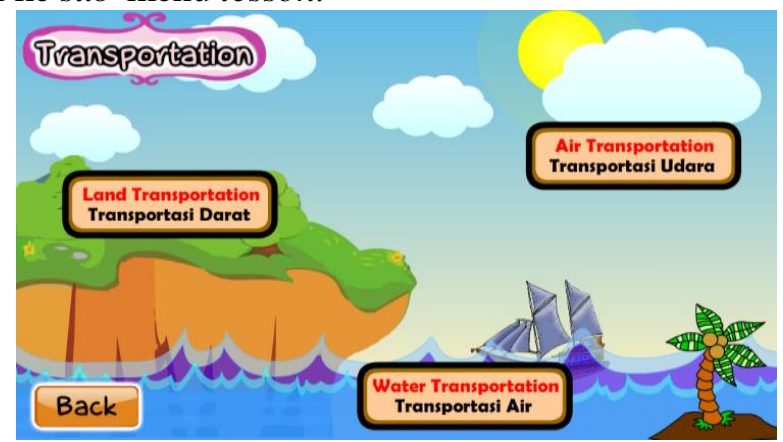

Gambar 7. User Interface Halaman Menu Transportation

8. Halaman Exercise

Halaman ini merupakan halaman untuk mengerjakan soal, pada halaman ini menampilkan 5(lima) pertanyaan dan ada 3 button untuk jawaban. 


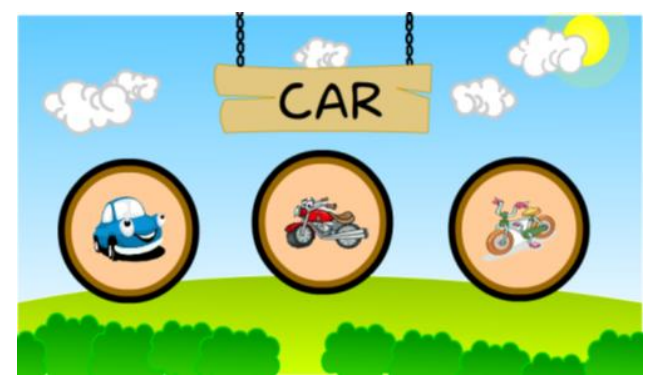

Gambar 8. Halaman Exercise

9. Halaman Games

Halaman ini menampilkan permainan tangkap huruf dan angka.

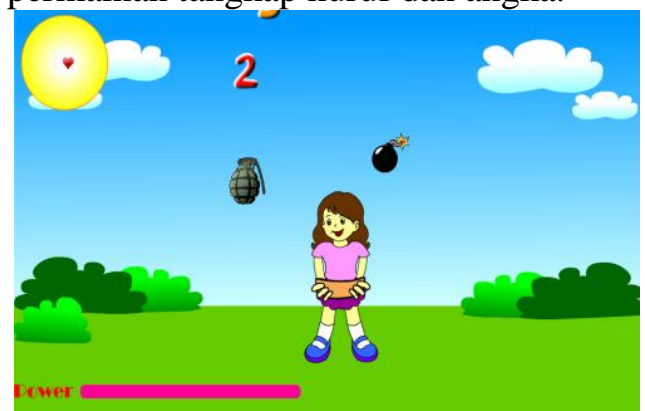

Gambar 9. User Interface Halaman Games

\section{Testing}

White Box

Hal yang dilakukan untuk testing white box yaitu:

1. Algoritma

Pada animasi interaktif ini dilakukan pengujian white box, Sebagai contoh akan dibahas pengujian games atau permainan terhadap level 1 (satu), yang prinsip kerjanya sama dengan level 2 (dua) dan level 3 (tiga) dari games ini. Secara garis besar, algoritma dari level 1 (satu) adalah sebagai berikut :

a) Pada permainan ini mempunyai 3 (tiga) level, Pada level 1 (satu) pemain diharuskan menangkap huruf, level 2 (dua) pemain diharuskan menangkap angka dan level 3 (tiga) pemain diharuskan menangkap huruf dan angka.

b) Jika pemain memiliki score atau nilai $<=100$, maka pemain mengulang kembali level tersebut.

c) Pemain dapat melanjutkan ke level berikutnya jika memiliki score atau nilai $>=100$.

d) Terdapat waktu 30 detik, jika pemain tidak dapat menyelesaikan permainan sebelum waktu yang disediakan maka pemain kalah dan pemain dapat mencoba lagi.

2. Bagan Alir

Dibawah ini merupakan gambar bagan alir permainan atau games : 


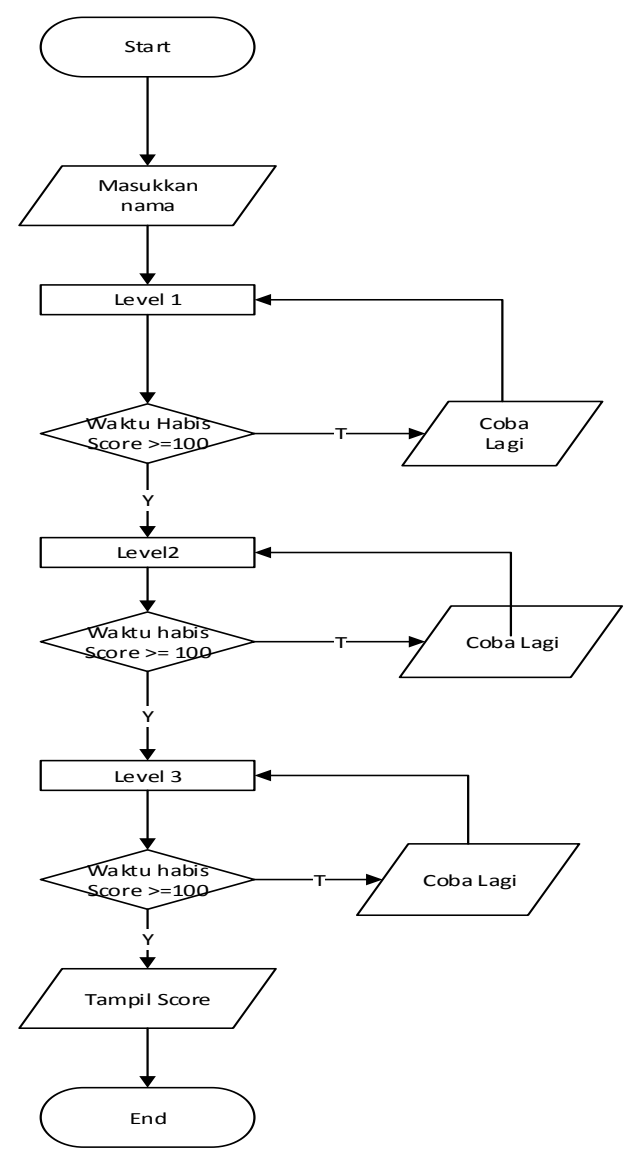

Gambar 10. Bagan Alir Menu Games

Dari bagan alir yang sudah dibuat maka dibuat grafik alir seperti dibawah ini :

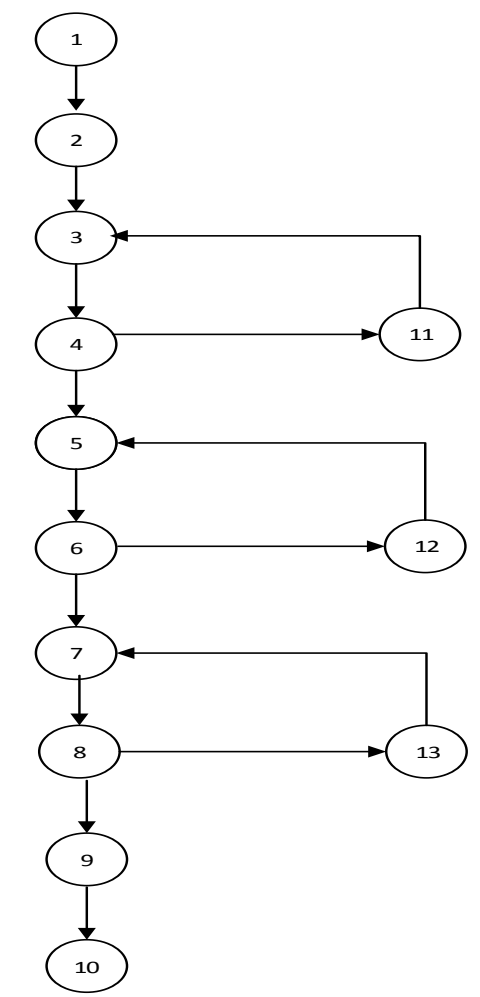

Gambar 11. Grafik Alir Menu Games 
Kompleksitas Siklomatis (pengukuran kuantitatif terhadap kompleksitas logis suatu program) dari grafik alir dapat diperoleh dengan perhitungan :

$$
\mathrm{V}(\mathrm{G})=\mathrm{E}-\mathrm{N}+2
$$

Dimana :

$\mathrm{E}=$ Jumah edge grafik alir yang ditandakan dengan gambar panah

$\mathrm{N}=$ Jumlah simpul grafik alir yang ditandakan dengan gambar lingkaran

Sehingga kompleksitas siklomatisnya :

$\mathrm{V}(\mathrm{G})=14-12+2=4$

Basis set yang dihasilkan dari jalur independent secara linier adalah jalur sebagai berikut :

$1-2-3-4-5-6-7-8-9-10$

$1-2-3-4-11-3-4-5-6-7-8-9-10$

$1-2-3-4-5-6-12-5-6-7-8-9-10$

$1-2-3-4-5-6-7-8-13-7-8-9-10$

Kesimpulannya bahwa terdapat 4 (empat) basis set yang dihasilkan dari jalu independent linier. Ketika aplikasi dijalankan, maka terlihat bahwa salah satu baris set yang dihasilkan adalah $1-2-3-$ $4-5-6-7-8-11-7-8-9-10$ dan terlihat bahwa simpul telah dieksekusi satu kali.

\section{Hasil Pengolahan Data Kuesioner}

Uji lapangan dilakukan di TK Islam An-Nurruddin, maka, yang harus mengisi kuesioner sebanyak 29 orang, yang terdiri dari Orang Tua Peserta Didik dan para Guru. Salah satu cara menentukan besaran sampel yang memenuhi hitungan adalah yang dirumuskan oleh Slovin, sebagai berikut:

$$
n=\frac{N}{1+N e^{2}}
$$

Keterangan :

$n$ : jumlah sampel

$\mathrm{N}$ : jumlah populasi

e: batas toleransi kesalahan (error tolerance)

Jadi, jumlah sampel yang harus mengisi kuesioner adalah

$\begin{aligned} \mathrm{n} & = & \frac{40}{40} \cdot 0,1^{2} \\ & = & \frac{40}{1,4} \\ & =28,5 & \end{aligned}$

Berikut ini adalah bagian dari Kuesioner Aplikasi Pengenalan Dasar Bahasa Inggris untuk peserta didik:

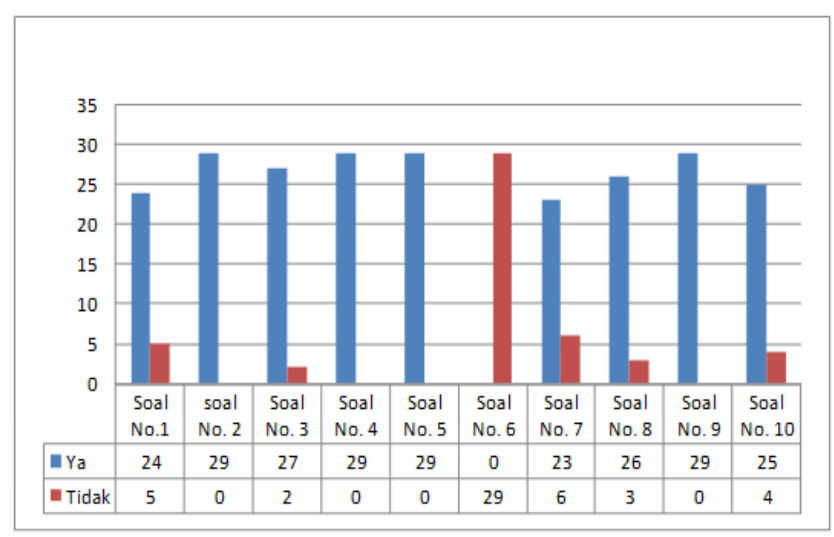

Gambar 12. Hasil Pengolahan Kuesioner Animasi 


\section{KESIMPULAN DAN SARAN}

Dari pembahasan pada penelitian ini dapat ditarik kesimpulan sebagai berikut :

1. Animasi interaktif pengenalan dasar Bahasa Inggris membuat peserta didik menarik untuk mempelajari dasar dari Bahasa Inggris.

2. Aplikasi pembelajaran ini menjadi salah satu alat bantu yang paling efektif untuk para Guru dalam menyampaikan materi dasar Bahasa Inggris kepada para Peserta Didik.

Beberapa saran guna untuk mengembangkan animasi kedepannya, sebagai berikut :

a. Lebih membuat lebih banyak lagi soal latihan yang terdapat pada menu exercise, agar anakanak lebih semangat lagi dalam menjawab soal-soal.

b. Tampilan yang terdapat di animasi tersebut dibuat lebih menarik lagi dengan ditambah efekefek animasi dan efek suara.

c. Games yang terdapat pada animasi tersebut perlu ditambahkan agar peserta didik tidak bosan dalam menggunakan animasi interaktif ini.

\section{DAFTAR PUSTAKA}

[1] Darma, Jarot.S, dan Shenia Ananda. 2009. Buku Pintar Menguasai Multimedia. Jakarta:Media Kita.

[2] Enterprise, Jubilee. 2010. 30 Bisnis Berbasis Ide Bagi Siapapun. Jakarta : PT. Elex Media Komputindo.

[3] Ramadhan, Arief, Taufik Muhlis, Panjhi Betha Yugara, Devi Juniati Tarigan dan Nurani Mustikasari.2006.36 Jam Belajar Komputer 3D Studio Max 7.Jakarta:Elex Media Komputindo

[4] Suardi, Moh.2015. Belajar \& Pembelajaran. Yogyakarta:DeePublish.

[5] Rizky, Soetam. 2011. Konsep Dasar Rekayasa Perangkat Lunak. Jakarta: PT. Prestasi Pustakaraya. 